\title{
Clostridium perfringens sepsis in three patients with acute leukemia and review of the literature
}

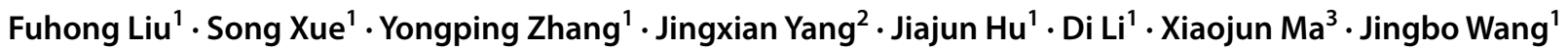

Received: 4 July 2020 / Revised: 7 December 2020 / Accepted: 7 December 2020 / Published online: 2 January 2021

(c) Japanese Society of Hematology 2021

\begin{abstract}
In this study, we aimed to improve understanding of the clinical manifestations, laboratory findings, and risk factors of Clostridium perfringens sepsis in patients with acute leukemia and to analyze treatment strategies for improving prognosis. We analyzed clinical manifestations, laboratory data, diagnosis, and treatment strategies in three cases of $C$. perfringens sepsis in patients with acute leukemia. We also reviewed and analyzed the relevant literature, incorporating our findings into the discussion. All three patients developed septic shock with neutropenia following chemotherapy. Analysis of blood samples confirmed the presence of $C$. perfringens, and two patients had fulminant intravascular hemolysis and developed multiple organ dysfunction syndrome. Two patients survived and one died despite timely and full-dose antibacterial treatments, blood purification, and noninvasive positive pressure ventilation. Overall, our findings showed that $C$. perfringens sepsis is rare in patients with acute leukemia but progresses rapidly. A high mortality rate was observed, and patients often experienced refractory shock and intravascular hemolysis. This demonstrates the importance of early detection and diagnosis. Multimodal treatments, including fluid resuscitation, antibiotics, organ support, and blood purification, are essential for success.
\end{abstract}

Keywords Clostridium perfringens $\cdot$ Acute leukemia $\cdot$ Sepsis $\cdot$ Intravascular hemolysis $\cdot$ Chemotherapy

\section{Introduction}

Clostridium perfringens is a Gram-positive anaerobic bacterium naturally found in the intestines. Intestinal dysbacteriosis can be caused by hypo-immunity or external factors,

Fuhong Liu and Song Xue contributed equally to this study as the first authors.

Xiaojun Ma and Jingbo Wang contributed equally to this study as the corresponding authors.

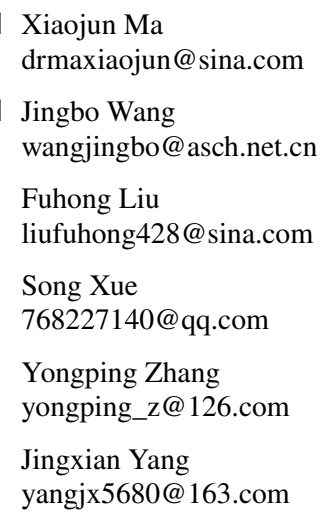

such as changes in the diet and drugs, and can result in $C$. perfringens sepsis [1]. C. perfringens sepsis is extremely rare in patients with acute leukemia; however, the mortality rate in these patients is very high. In this article, we describe three cases of $C$. perfringens sepsis in patients with acute leukemia. We aimed to provide insights into the progression of this disease and methods for treating it.

Jiajun $\mathrm{Hu}$

hjj1975ht@sina.com

1 Department of Hematology, Aerospace Center Hospital, No. 15 Yu Quan Road, Beijing 100049, China

2 Department of Laboratory, Aerospace Center Hospital, Peking University Aerospace School of Clinical Medicine, Beijing, China

3 Department of Infectious Diseases, Peking Union Medical College Hospital, No. 1 Shuai Fu Yuan, Beijing 100005, China 


\section{Case report}

Case 1 was a 21 -year-old man who was diagnosed with acute myeloid leukemia 5 years prior. He relapsed after multiple chemotherapy and was admitted to the hospital in October 2018, where he underwent chemotherapy with idarubicin, cytarabine, and teniposide. Fluconazole was empirically applied to prevent fungal infections after chemotherapy. Twelve days after chemotherapy, his neutrophil counts decreased to $0.04 \times 109 / \mathrm{L}$ and he experienced chills and hypotension during a homotype platelet transfusion. His blood pressure rebounded after methylprednisolone treatment; however, he soon was found to have a fever. Aerobic and anaerobic bacteria cultures were performed from the peripheral vessel and venous infusion port, and he was given meropenem at $0.5 \mathrm{~g}$ every $6 \mathrm{~h}$. Six hours later, he showed signs of shock, and his skin and mucous membranes turned yellow. His blood pressure was $85 / 40 \mathrm{mmHg}, \mathrm{SpO}_{2}$ was $93 \%$, and heart rate was $130 \mathrm{bpm}$. Following active fluid replacement and stabilization of pressure, the patient discharged brown urine. Analysis indicated the occurrence of neutropenia, decreased hemoglobin, increased bilirubin, and acute renal failure. Lactate dehydrogenase (reference range 120-250 U/L) increased (up to $1607 \mathrm{U} / \mathrm{L}$ ), B-type natriuretic peptide (reference range 0-100 pg/mL) increased (up to $1879 \mathrm{pg}$ / $\mathrm{mL}$ ), D-dimer increased (up to $25,798 \mu \mathrm{g} / \mathrm{L}$ ), and procalcitonin increased (exceeding $100 \mathrm{ng} / \mathrm{mL}$; Fig. 1). The patient was promptly moved to the intensive care unit (ICU) and administered 500-mg methylprednisolone to relieve hemolysis. Meropenem was increased to $2 \mathrm{~g}$ every $8 \mathrm{~h}$ (patient weight $120 \mathrm{~kg}$ ). Recombinant human granulocyte-stimulating factor (G-CSF) was subcutaneously administered to increase the white cells, and the venous infusion port was removed. Continuous blood purification (hemofiltration) and noninvasive high-flow positive pressure ventilation were performed. Three days later, the patient showed signs of recovery, white blood cell counts increased, and liver function was improved. However, kidney function did not significantly improve (Fig. 1). Antibiotics and hemofiltration were continually administered, and kidney function improved after 20 days (Fig. 1). Gram-positive bacilli were subsequently observed in two anaerobic blood cultures after $12 \mathrm{~h}$; the bacteria were identified as $C$. perfringens. Candida was also found in cultures during the same period. Upon questioning, the patient indicated that he had consumed expired yogurt 1 day before the onset of fever. Abdominal computed tomography revealed no pneumobilia. Gradually, the patient recovered and resumed chemotherapy treatment.

Case 2 was a 42-year-old man who had been diagnosed with acute myeloid leukemia after the enlargement of lymph glands, which did not respond to chemotherapy treatment for 3 months. The patient showed resistance to the use of traditional drugs and was given daratumumab in September 2019. Fluconazole was empirically applied to prevent fungal infections during neutropenia, and his neutrophil counts decreased to $0.27 \times 109 / \mathrm{L}$. The patient experienced mild abdominal pain, fever, and chills at night after eating rotten peaches for dinner; however, his oxygen levels and blood pressure were normal. A blood sample was obtained from the peripheral vessel and peripherally inserted central catheter (PICC), and meropenem $0.5 \mathrm{~g}$ every $6 \mathrm{~h}$ was administered to combat infection. The patient showed low blood pressure $(83 / 42 \mathrm{mmHg})$, low blood oxygen levels (SpO2: 89\%), and a heart rate of $135 \mathrm{bpm}$ after $5 \mathrm{~h}$. Brown-colored urine was also discharged. Blood tests showed significant declines in bilirubin and hemoglobin, a lack of kidney function, elevated hyperkalemia levels (up to $20.14 \mathrm{mg} / \mathrm{mL}$ ) and lactate dehydrogenase levels (up to $4723 \mathrm{U} / \mathrm{L}$ ), an increase in procalcitonin (maximum $20.14 \mathrm{ng} / \mathrm{mL}$ ), an increase in B-type natriuretic peptide (maximum $4027 \mathrm{pg} / \mathrm{mL}$ ), and an increase in D-dimer (maximum 10,374 $\mu \mathrm{g} / \mathrm{L}$; Fig. 2). The patient was placed in the ICU and assessed for sepsis. Meropenem was increased to $1 \mathrm{~g}$ every $8 \mathrm{~h}$, and penicillin $(4 \times 106 \mathrm{U}$ every $6 \mathrm{~h})$ was administered to combat infection. In addition, 500-mg methylprednisolone was administered to stop hemolysis, and recombinant human G-CSF was subcutaneously administered to increase white blood cells. The PICC was removed, and noninvasive high-flow positive pressure ventilation and continuous blood purification (hemofiltration) were performed. However, the patient's condition did not improve (Fig. 2). Instead, rapid severe metabolic acidosis occurred, blood oxygen continued to decline, and black bacterial plaques appeared on the abdominal skin of the patient. Despite the active measures taken to treat the patient, including sodium bicarbonate correction for acidosis, ventilator-assisted breathing, and norepinephrine boosting, the patient died $24 \mathrm{~h}$ later. The anaerobic samples cultured for $8 \mathrm{~h}$ showed the presence of Gram-positive bacilli (Fig. 3), which were later identified as $C$. perfringens.

Case 3 was a 58-year-old woman who had been diagnosed with acute myeloid leukemia after experiencing fatigue for 5 months. Following chemotherapy, her bone marrow was recovered. In September 2019, she underwent high-dose cytarabine chemotherapy. Fluconazole was empirically applied to prevent fungal infections after chemotherapy. Thirteen days after chemotherapy, the patient's neutrophil count decreased to $0.01 \times 109 / \mathrm{L}$, and she developed a fever $\left(39^{\circ} \mathrm{C}\right)$, abdominal pains, nausea, mild diarrhea, and chills. Her vital signs were stable. Blood samples were obtained (from the peripheral vessel and PICC), meropenem at $0.5 \mathrm{~g}$ every $6 \mathrm{~h}$ was administered, and the patient's temperature 
Fig. 1 Key laboratory indexes in case 1

\section{Key laboratory indexes in case 1}

900

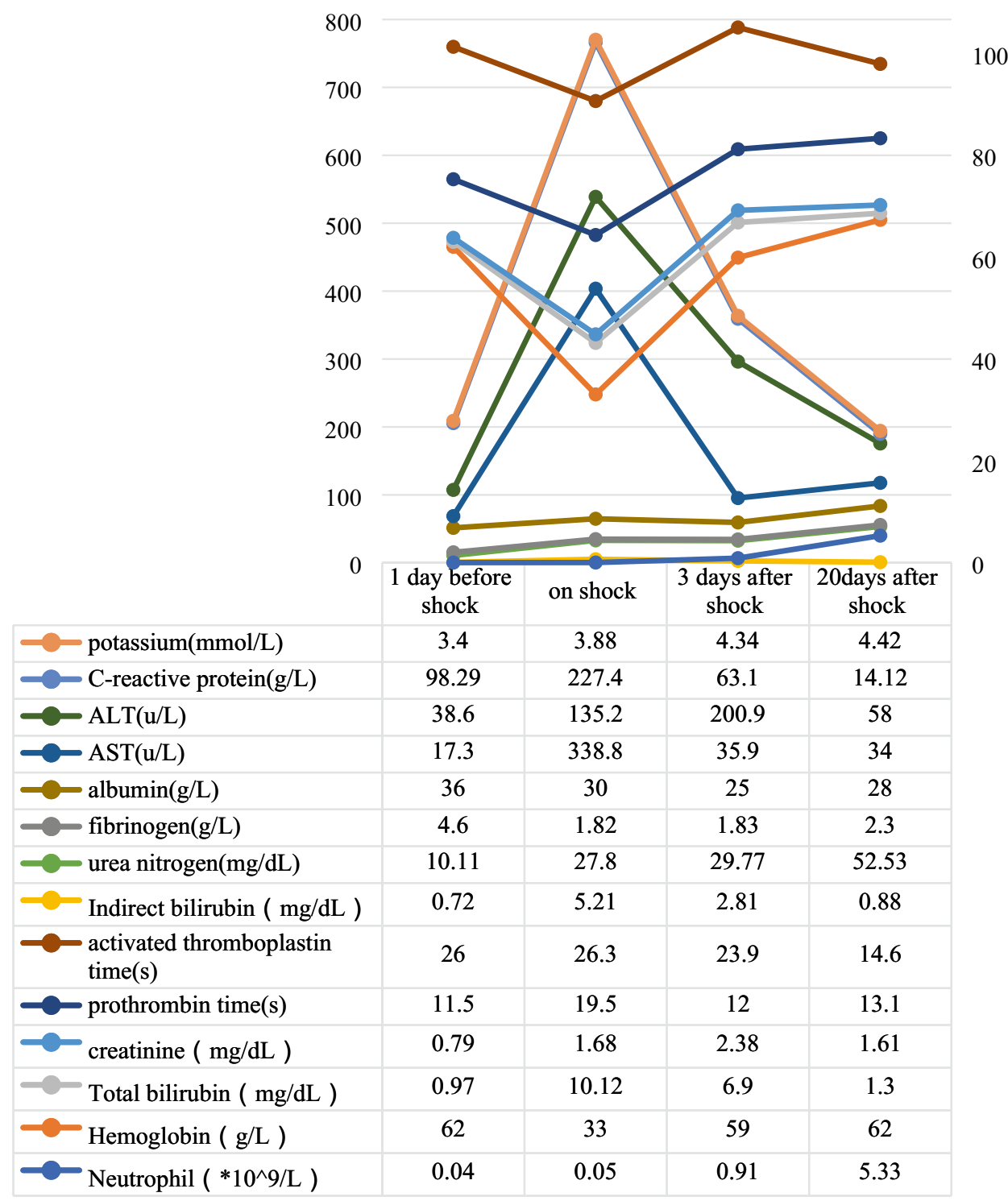

dropped to $38.2{ }^{\circ} \mathrm{C}$. The patient had a fever for $36 \mathrm{~h}$ and then experienced abdominal distension and mild pain in the upper abdomen. A decrease in blood pressure followed, reaching a minimum of $70 / 35 \mathrm{mmHg}$. Blood oxygen levels were normal, and inflammation indicators increased. The kidneys and liver showed normal function (Fig. 4). The patient experienced septic shock and was given fluid boosters. Meropenem at $1 \mathrm{~g}$ every $8 \mathrm{~h}$ was given. Moreover, although the dose of meropenem was increased, we considered that there might be resistance to carbapenem drugs, and we empirically added penicillin $(4 \times 106 \mathrm{U}$ every $6 \mathrm{~h})$ to further combat infection and G-CSF to stimulate the white blood cell count; the patients temperature then returned to normal (Fig. 4). Anaerobic samples cultured for $24 \mathrm{~h}$ contained Gram-positive bacilli, which were identified as $C$. perfringens. Abdominal computed tomography revealed no pneumobilia. Fortunately, the patient survived and resumed chemotherapy.

These three cases are summarized in Table 1

\section{Review of the literature}

Patients with leukemia have compromised immune systems, increasing their risk of infection and making them vulnerable to $C$. perfringens infections. Within a 35-year period (1985-2020), only 12 studies (10 published in English and 
Fig. 2 Key laboratory indexes in case 2

\section{Key laboratory indexes in case 2}

25000

15000

- potassium(mmol/L)

\begin{tabular}{|c|c|c|c|}
\hline $\begin{array}{c}\text { 1day before } \\
\text { shock }\end{array}$ & on shock & $\begin{array}{c}12 \mathrm{~h} \text { after } \\
\text { shock }\end{array}$ & $\begin{array}{c}24 \mathrm{~h} \text { after } \\
\text { shock }\end{array}$ \\
\hline 4.03 & 4.61 & 5.15 & 5.62 \\
\hline 0.91 & 54.3 & 60.35 & 78.86 \\
\hline 73.5 & 132 & 6713 & 9082 \\
\hline 33.4 & 346 & 5446 & 12684 \\
\hline 32 & 31 & 22 & 23 \\
\hline 3.59 & 0.01 & 0.01 & 0.01 \\
\hline 32.02 & 52.53 & 35.11 & 30.62 \\
\hline 0.51 & 0.98 & 3.95 & 4.91 \\
\hline 12.9 & 28.7 & 53.4 & 49.5 \\
\hline 11 & 16.6 & 28.6 & 26.4 \\
\hline 0.73 & 1.07 & 1.4 & 1.73 \\
\hline 0.64 & 1.29 & 5.6 & 8.06 \\
\hline 70 & 44 & 37 & 53 \\
\hline 0.27 & 1.2 & 0.35 & 0.07 \\
\hline
\end{tabular}

two published in Chinese) have been reported describing cases of $C$. perfringens infection in patients with leukemia (searched for using the terms "leukemia", "leukemias", "Clostridium", "perfringens", and "C. perfringens" in PubMed and the terms "leukemia" and "Clostridium perfringens" in Wanfang). With the three cases reported in this study, only 17 cases of $C$. perfringens infection in patients with leukemia have been reported. Of the 17 patients, two were female $(11.8 \%)$ and 15 were male $(88.2 \%)$. The median age was 46 years (age range 14-74); six had acute lymphocytic leukemia (35.3\%) and 11 had acute myeloid leukemia (64.7\%). Thirteen patients experienced shock (76.5\%), 16 patients experienced neutropenia, 10 patients experienced intravascular hemolysis $(58.8 \%)$, and six patients experienced renal dysfunction (35.3\%). Moreover, 10 patients died $(58.8 \%)$, and seven patients survived (41.2\%). Of the 10 who died, all passed within $48 \mathrm{~h}$ of onset (range 6-48 h). In addition, seven of 10 patients with hemolysis died, whereas all surviving patients did not have hemolysis (Table 2).

\section{Discussion}

Clostridium perfringens was first discovered in 1891 after William H. Welch performed an autopsy on a 38-yearold man [2]. This organism is a Gram-positive, anaerobic 


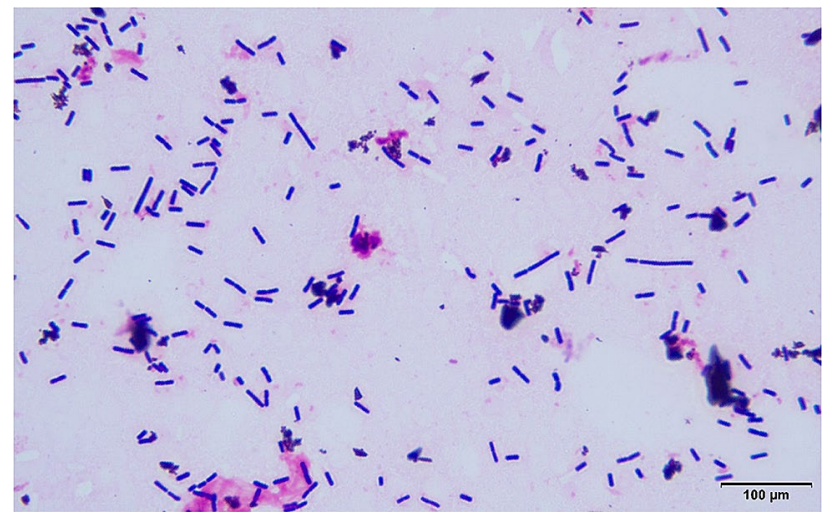

Fig. 3 Gram staining of a peripheral blood smear reveal Gram-positive bacillus

bacillus found in colonies in the human reproductive tract and intestines. Food poisoning, muscle necrosis, and gas gangrene are all caused by $C$. perfringens [3]. Individuals with poorly managed diabetes, cirrhosis, chemotherapyinduced neutropenia, malignancies, and old age are at a high risk for infection [4]. In addition, patients with acute leukemia, particularly agranulocytosis, are at a particularly high risk [5]. Of the three patients in our study, two had a history of poor diet, and one displayed abdominal symptom. These findings suggested that the intestinal flora could be altered and that the bacteria could penetrate the mucosal lining following damage, resulting in the disruption of blood flow when low levels of granulocytes are present [6].

In patients with fever, shock, intravascular hemolysis, and renal failure, $C$. perfringens sepsis should be considered, especially for patients with acute leukemia during neutropenia. C. perfringens sepsis is rare but fatal [7]. Indeed, approximately $7-15 \%$ of patients experience a high level of intravascular hemolysis [8], which can be easily overlooked and is often associated with other rare diseases, such as malaria, bartonellosis, and babesiosis infection. Moreover, infection by this bacterium is also associated with noninfectious symptoms, such as reactions to blood transfusions, paroxysmal nocturnal hemoglobinuria, and deficiencies in glucose 6-phosphate dehydrogenase. After significant intravascular hemolysis, the mortality rate increases, reaching up to $80 \%$ in patients with hemolysis, as demonstrated in a study of 40 adult patients with a median time from onset to death of $8 \mathrm{~h}$ [8]. Another study of 50 adults showed that the mortality rate was $74 \%$ in patients with $C$. perfringens sepsis, with a median time to death of $9.7 \mathrm{~h}$ [9]. In the cases screened from our literature review in this study, seven of the 10 patients with leukemia who had hemolysis died, whereas all surviving patients did not have hemolysis.

Clostridium perfringens can produce a significant amount of protein toxins, particularly alpha toxin (the primary pathogenic indicator of hemolysis and gas gangrene). One toxin is phospholipase $\mathrm{C}$ lecithinase, which in the membranes of red blood cells, induces hydrolysis of phospholipids, thereby resulting in intravascular hemolysis. In platelets, leukocytes, muscle cells, and endothelial cells, this toxin lyses the plasma membrane [10]. Alpha toxins also affect how immune cells (such as neutrophils) are transferred to infected tissues, which could lower pathogen clearance at the infection site. Increased inflammation during metabolism in the host cell could cause an immune system response, resulting in damaged tissues [11, 12].

With the exception of the induction of intravascular hemolysis, $C$. perfringens sepsis exhibits the same general clinical manifestations as other types of sepsis, including shock, organ failure (particularly renal failure), and fever [13]. The most important part of treating patients with this disease is to identify the infection early and to quickly administer appropriate antibacterial agents. $C$. perfringens sepsis is often not the only infection present in a patient, and it might, therefore, be preferable to use antibacterial drugs that target a wide range of infections [14]. Some researchers have observed that using both penicillin and tetracyclines or clindamycin quickly stops the production of toxins, and treatment with high doses of erythromycin and cephalosporins is also effective [15]. We primarily used meropenem to treat the infection owing to granulocytic deficiency. Patients with symptoms of a $C$. perfringens infection (e.g., reports of Gram-positive short, coarse bacilli and hemolysis) also received high doses of penicillin. Patients with leukemia exhibiting agranulocytosis are vulnerable to fungal infection and also received antifungal treatment. With the exception of the antibacterial regimen, patients were infected during agranulocytosis, suggesting that applying G-CSF early could manage agranulocytosis and improve prognosis for patients with $C$. perfringens infection [16]. In addition, treating the infected area with hyperbaric oxygen therapy and surgery has also been shown to be effective [17]. Patients with leukemia are also susceptible to infection via a central venous catheter. Accordingly, we closed the central venous catheter of all three patients as quickly as possible. We then re-established venous access and removed the old catheter to reduce the chance of infection.

Six of the 17 cases collected in our literature review exhibited renal failure, and four of these patients were treated with blood purification, an important step in combatting septic shock [18]. The three most advanced technologies for purifying blood to treat septic shock are those that adsorb blood to remove inflammatory mediators or endotoxins in patients with sepsis, those that allow for a high volume of hemofiltration, and those that allow for integrated or hybrid blood purification $[19,20]$. Techniques integrating blood purification combine technology for plasma and blood adsorption with continuous renal replacement therapy (CRRT), using several filters to treat septic shock. In these 
Fig. 4 Key laboratory indexes in case 3

\section{Key laboratory indexes in case 3}

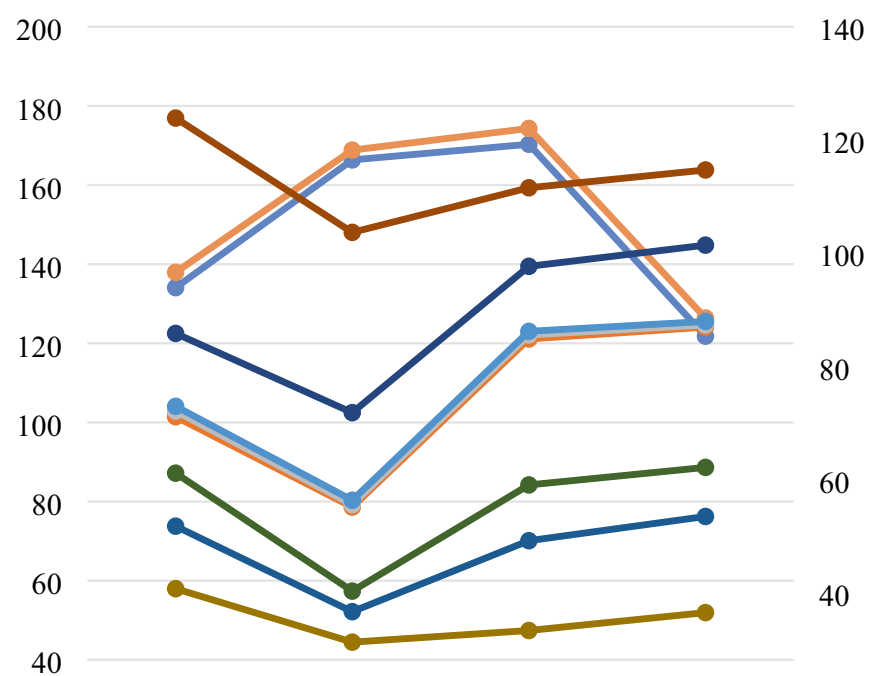

\begin{tabular}{|c|c|c|c|c|}
\hline 0 & $\begin{array}{l}\text { 1day before } \\
\text { shock }\end{array}$ & on shock & $\begin{array}{c}1 \text { day after } \\
\text { shock }\end{array}$ & $\begin{array}{l}5 \text { days after } \\
\text { shock }\end{array}$ \\
\hline$-\operatorname{potassium}(\mathrm{mmol} / \mathrm{L})$ & 3.87 & 2.48 & 4 & 4.6 \\
\hline - C-reactive protein $(\mathrm{g} / \mathrm{L})$ & 46.9 & 109 & 86.12 & 33.17 \\
\hline$-\operatorname{ALT}(\mathrm{u} / \mathrm{L})$ & 13.4 & 5.2 & 14.1 & 12.4 \\
\hline$-\operatorname{AST}(\mathrm{u} / \mathrm{L})$ & 15.8 & 7.7 & 22.7 & 24.3 \\
\hline - albumin $(\mathrm{g} / \mathrm{L})$ & 40 & 36 & 28 & 34 \\
\hline - fibrinogen $(\mathrm{g} / \mathrm{L})$ & 3.09 & 3.37 & 2.87 & 2.21 \\
\hline - urea nitrogen $(\mathrm{mg} / \mathrm{dL})$ & 14.04 & 4.77 & 16.01 & 15.45 \\
\hline Indirect bilirubin $(\mathrm{mg} / \mathrm{dL})$ & 0.84 & 0.32 & 0.52 & 0.27 \\
\hline $\begin{array}{l}\text { activated thromboplastin } \\
\text { time(s) }\end{array}$ & 38.1 & 31.9 & 13.9 & 13.3 \\
\hline prothrombin time(s) & 12.9 & 15.5 & 11.5 & 13.5 \\
\hline creatinine $(\mathrm{mg} / \mathrm{dL})$ & 0.85 & 0.78 & 0.64 & 0.62 \\
\hline Total bilirubin ( $\mathrm{mg} / \mathrm{dL})$ & 0.99 & 0.43 & 0.71 & 0.38 \\
\hline Hemoglobin $(\mathrm{g} / \mathrm{L})$ & 71 & 55 & 84 & 81 \\
\hline Neutrophil (*10^9/L ) & 0.01 & 0.02 & 0.77 & 5.87 \\
\hline
\end{tabular}

two techniques, CRRT can filter small and medium-sized molecules associated with inflammation, which stabilizes the internal environment. Techniques related to blood and plasma adsorption can filter medium and large molecules associated with inflammation and endotoxins, which is more helpful when removing homeostasis and toxins [21]. In certain cases, the disease progresses despite taking early preventative measures, such as administering antibacterial drugs, purifying the blood, and removing sources of infection. For example, in our case 2, these early treatments still resulted in multiple organ failure. This could be because of the high bacterial load in the patient's blood, resulting in increased levels of toxins (despite hemofiltration). Combining adsorption with integrated hemofiltration technology could be a more appropriate treatment to remove endotoxins and inflammatory mediators from the blood of such patients. In addition, in a case of gas gangrene, researchers attempted to apply polymyxin B-immobilized fiber column direct hemoperfusion; however, this treatment failed [32].

Clostridium perfringens sepsis is an infection that is extremely rare in patients with acute leukemia. However, this disease is extremely dangerous and is associated with a high mortality rate. It is essential to administer antibacterial drugs as early as possible. In addition, management 


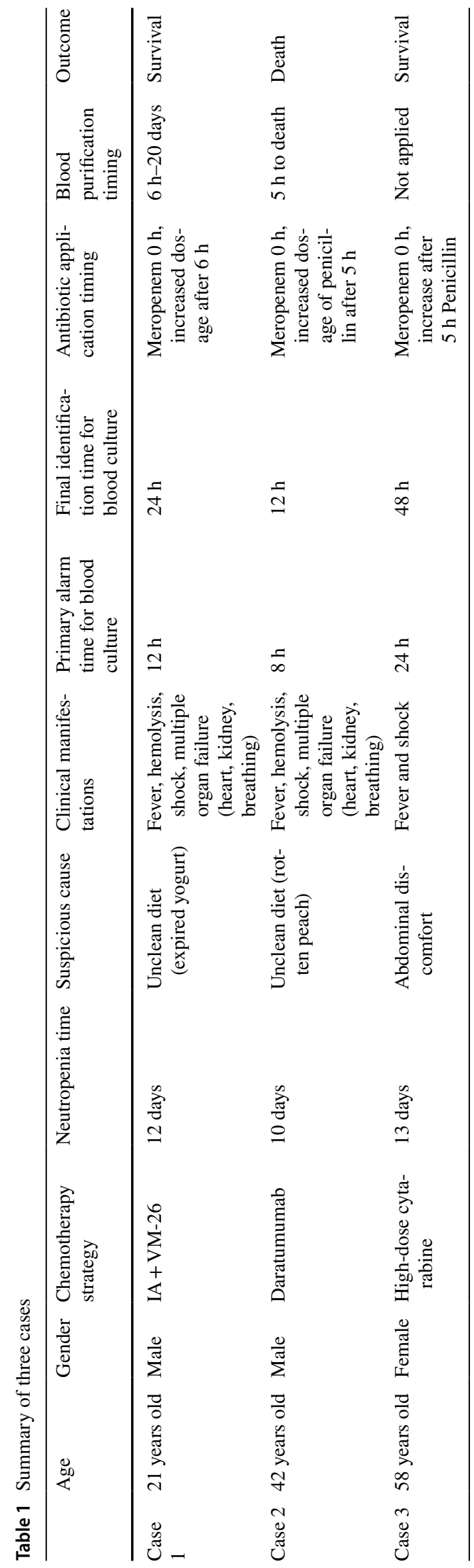

strategies should aim to support organ function and shorten the time of neutropenia. Finally, combining adsorption technologies with hemofiltration might facilitate the treatment of $C$. perfringens sepsis. 


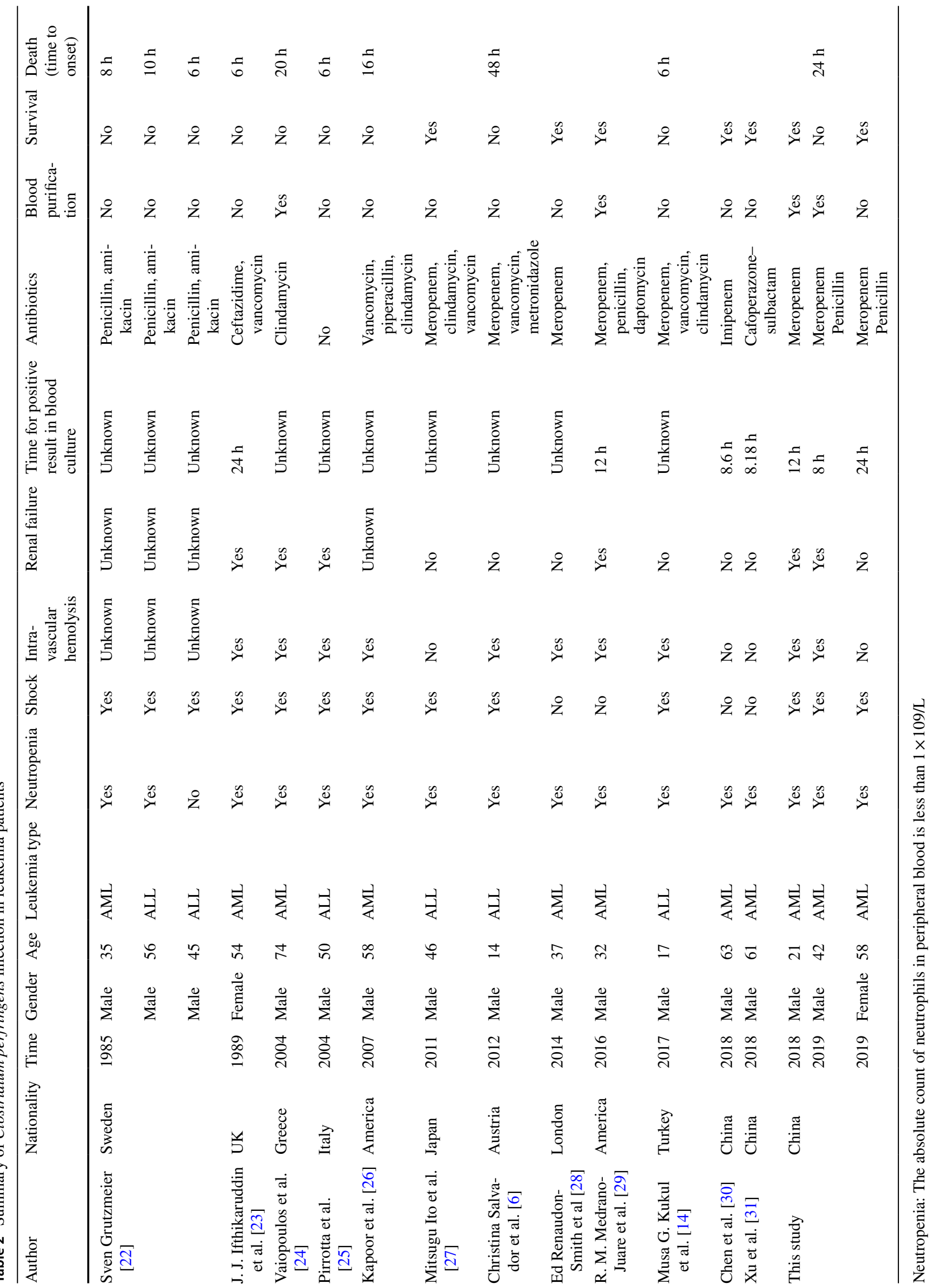


Acknowledgements We thank the medical staff of our ICU wards for the excellent care of our patients, and thank the department of laboratory for cultivation and identification of this bacteria.

Author contributions FL and SX performed the data analyses and wrote the manuscript. These authors contributed equally to this study as the first authors. YZ, JY, JH, and DL contributed to the conception of the study. JW and XM contributed significantly to analysis and manuscript preparation. These authors contributed equally to this study as corresponding authors.

Funding This work was supported by the China Capital Characteristic Clinic Project (Grant No. Z171100001017103).

Data availability All data used during the study appear in the submitted article.

\section{Compliance with ethical standards}

Conflict of interest The authors declare no competing financial interests.

Informed consent The patients provided written informed consent for the publication of this case report. All the procedures performed in this study involving the use of human subjects were performed in accordance with the ethical standards of the China Aerospace Center Hospital Institution Review Board and with the 1964 Declaration of Helsinki and its later amendments or comparable ethical standards.

\section{References}

1. Fernandez R, Anampa-Guzman A. Septic shock due to Clostridium perfringens. Cureus. 2019;11(3):e4262.

2. Welch WH. A gas-producing bacillus capable of rapid development in the blood vessels after death. Bull Johns Hopkins Hosp. 1892;1892(3):81.

3. Fafangel M, Ucakar V, Vudrag M, Berce I, Kraigher A. A five site Clostridium perfringens food-borne outbreak: a retrospective cohort study. Zdravstveno Varstvo. 2015;54(1):51-7.

4. Yang CC, Hsu PC, Chang HJ, Cheng CW, Lee MH. Clinical significance and outcomes of Clostridium perfringens bacteremia-a 10-year experience at a tertiary care hospital. IJID. 2013;17(11):e955-60.

5. Yamamoto Y, Itoh N, Sugiyama T, Kurai H. Clinical features of Clostridium bacteremia in cancer patients: a case series review. J Infect Chemother. 2020;26(1):92-4.

6. Salvador C, Kropshofer G, Niederwanger C, Trieb T, Meister $\mathrm{B}, \mathrm{Neu} \mathrm{N}$, et al. Fulminant Clostridium perfringens sepsis during induction chemotherapy in childhood leukemia. Pediatr Int. 2012;54(3):424-5.

7. Fujikawa H, Araki M. Clostridium perfringens septicemia with massive intravascular hemolysis. Intern Med. 2020;59(4):591.

8. van Bunderen CC, Bomers MK, Wesdorp E, Peerbooms P, Veenstra J. Clostridium perfringens septicaemia with massive intravascular haemolysis: a case report and review of the literature. Neth J Med. 2010;68(9):343-6.

9. Simon TG, Bradley J, Jones A, Carino G. Massive intravascular hemolysis from Clostridium perfringens septicemia: a review. J Intensive Care Med. 2014;29(6):327-33.

10. Navarro MA, McClane BA, Uzal FA. Mechanisms of action and cell death associated with Clostridium perfringens toxins. Toxins (Basel). 2018;10(5):212.
11. Takehara M, Seike S, Sonobe Y, Bandou H, Yokoyama S, Takagishi $\mathrm{T}$, et al. Clostridium perfringens alpha-toxin impairs granulocyte colony-stimulating factor receptor-mediated granulocyte production while triggering septic shock. Communications biology. 2019;2:45.

12. Kiu R, Hall LJ. An update on the human and animal enteric pathogen Clostridium perfringens. Emerg Microbes Infect. 2018;7(1):141.

13. Fujita H, Nishimura S, Kurosawa S, Akiya I, Nakamura-Uchiyama F, Ohnishi K. Clinical and epidemiological features of Clostridium perfringens bacteremia: a review of 18 cases over 8 year-period in a tertiary care center in metropolitan Tokyo area in Japan. Intern Med. 2010;49(22):2433-7.

14. Kukul MG, Ciki K, Karadag-Oncel E, Cengiz AB, Kuskonmaz $\mathrm{B}$, Tavil $\mathrm{B}$, et al. A fatal Clostridium perfringens infection with hemolysis after chemotherapy in an adolescent. Arch Argent Pediatr. 2017;115(2):e92-5.

15. Bryant AE, Stevens DL. Clostridial myonecrosis: new insights in pathogenesis and management. Curr Infect Dis Rep. 2010;12(5):383-91

16. Barnes C, Gerstle JT, Freedman MH, Carcao MD. Clostridium septicum myonecrosis in congenital neutropenia. Pediatrics. 2004;114(6):e757-60.

17. Millard MA, McManus KA, Wispelwey B. Severe sepsis due to Clostridium perfringens bacteremia of urinary origin: a case report and systematic review. CRIID. 2016;2016:2981729.

18. Rhodes A, Evans LE, Alhazzani W, Levy MM, Antonelli M, Ferrer $\mathrm{R}$, et al. Surviving sepsis campaign: international guidelines for management of sepsis and septic shock: 2016. Intensive Care Med. 2017;43(3):304-77.

19. Payen DM, Guilhot J, Launey Y, Lukaszewicz AC, Kaaki M, Veber B, et al. Early use of polymyxin B hemoperfusion in patients with septic shock due to peritonitis: a multicenter randomized control trial. Intensive Care Med. 2015;41(6):975-84.

20. Honore PM, Matson JR. Extracorporeal removal for sepsis: acting at the tissue level-the beginning of a new era for this treatment modality in septic shock. Crit Care Med. 2004;32(3):896-7.

21. Ronco C, Brendolan A, Lonnemann G, Bellomo R, Piccinni P, Digito A, et al. A pilot study of coupled plasma filtration with adsorption in septic shock. Crit Care Med. 2002;30(6):1250-5.

22. Grutzmeier S. Clostridium perfringens septicemia and acute leukemia. Acta Medica Scandinavica. 1985;218(3):341-3.

23. Ifthikaruddin JJ, Holmes JA. Clostridium perfringens septicaemia and massive intravascular haemolysis as a terminal complication of autologous bone marrow transplant. Clin Lab Haematol. 1992;14(2):159-61.

24. Vaiopoulos G, Calpadaki C, Sinifakoulis H, Konstantopoulos K, Avlami A, Stefanou J, et al. Massive intravascular hemolysis: a fatal complication of Clostridiumperfringens septicemia in a patient with acute myeloid leukemia. Leuk Lymphoma. 2004:45(10):2157-9.

25. Pirrotta MT, Bucalossi A, Forconi F, Gozzetti A, Bocchia M, Mazzotta S, et al. Massive intravascular hemolysis: a fatal complication of Clostridium perfringens septicemia in a patient with acute lymphoblastic leukemia. Leuk Lymphoma. 2005;46(5):793.

26. Kapoor JR, Monteiro B, Tanoue L, Siegel MD. Massive intravascular hemolysis and a rapidly fatal outcome. Chest. 2007;132(6):2016-9.

27. Ito M, Takahashi N, Saitoh H, Shida S, Nagao T, Kume M, et al. Successful treatment of necrotizing fasciitis in an upper extremity caused by Clostridium perfringens after bone marrow transplantation. Intern Med. 2011;50(19):2213-7.

28. Renaudon-Smith E, Kaur M, Haroon A, Cavenagh J, Butler T. Intravascular haemolysis secondary to Clostridium perfringens in a patient with acute myeloid leukaemia undergoing allogeneic stem cell transplantation. Br J Haematol. 2014;165(6):743. 
29. Medrano-Juarez RM, Sotello D, Orellana-Barrios MA, D’Cuhna L, Payne JD, Nugent K. Acute hemolysis with renal failure due to Clostridium bacteremia in a patient with AML. Case Reports in Infectious Diseases. 2016;2016:6549268.

30. Chen D, Cao J, Wang Y, Qang Y, Zhang H. Clinical and etiological analysis of a case of bloodstream infection caused by Clostridium perfringens. Laboratory Med Clin. 2018;15(18):49.

31. Xu C, Su Y, Tian Z. A case report and literature review of a patient with hematological malignancy complicated by Clostridium perfringens. CJIC. 2018;17(3):270-2.
32. Takazawa T, Ohta J, Horiuchi T, Hinohara H, Kunimoto F, Saito $\mathrm{S}$. A case of acute onset postoperative gas gangrene caused by Clostridium perfringens. BMC Res Notes. 2016;9:385.

Publisher's Note Springer Nature remains neutral with regard to jurisdictional claims in published maps and institutional affiliations. 